\title{
Diagnostic value of MUC4 immunostaining in distinguishing epithelial mesothelioma and lung adenocarcinoma
}

Karine Llinares $^{1,2}$, Fabienne Escande ${ }^{1,3}$, Sébastien Aubert ${ }^{1,2}$, Marie-Pierre Buisine ${ }^{1,3}$, Carme de Bolos $^{4}$, Surinder K Batra ${ }^{5}$, Bernard Gosselin ${ }^{2}$, Jean-Pierre Aubert ${ }^{1,3}$, Nicole Porchet ${ }^{1,3}$ and Marie-Christine Copin ${ }^{1,2}$

${ }^{1}$ Unité INSERM U560 Laboratoire de Recherche Gérard Biserte, Place de Verdun, Lille, France; ${ }^{2}$ Department of Pathology, Hôpital A Calmette; ${ }^{3}$ Department of Biochemistry and Molecular Biology, Hôpital C Huriez, CHRU Lille, France; ${ }^{4}$ Unitat de Biologia Cellular i Molecular, Institut Municipal d'Investigacio Medica, Barcelona, Spain and ${ }^{5}$ Department of Biochemistry and Molecular Biology, UNMC/Eppley Cancer Center, University of Nebraska Medical Center, NE, USA

\begin{abstract}
The distinction between pleural malignant mesothelioma and pleural infiltration by adenocarcinomas has complex therapeutic and medicolegal implications. Although the panel of adenocarcinoma-associated antibodies and one or two mesothelioma markers is useful in this purpose, most of these antibodies are not totally specific. We determined the diagnostic value of MUC4 immunostaining in this issue. MUC4 gene expression was also studied by in situ hybridization and RT-PCR. MUC4 is a membrane-bound mucin that has been suggested to be implicated in malignant progression in humans and rats. The MUC4 gene is expressed in various normal epithelial tissues of endodermic origin and carcinomas. In the respiratory tract, MUC4 transcripts have been detected in normal respiratory epithelium and lung carcinomas. MUC4 protein was expressed in 32 of $35(91.4 \%)$ lung adenocarcinomas on paraffin-embedded tissue. None of the 41 malignant mesotheliomas nor the 32 cases of benign mesothelial cells expressed MUC4 at the protein and mRNA levels. We conclude that MUC4 is a very specific (100\%) and sensitive $(91.4 \%)$ marker of lung adenocarcinomas on paraffin-embedded tissue that could be useful in diagnostic practice in the distinction between malignant mesothelioma and adenocarcinoma.
\end{abstract}

Modern Pathology (2004) 17, 150-157, advance online publication, 5 December 2003; doi:10.1038/modpathol.3800027

Keywords: mucin; malignant mesothelioma; adenocarcinoma; immunohistochemistry; differential diagnosis

Immunohistochemistry provides an important tool for distinguishing pleural malignant mesothelioma from peripheral lung adenocarcinoma invading the pleura or from a metastatic adenocarcinoma arising in a distant organ. This distinction has complex therapeutic and medicolegal implications. ${ }^{1,2}$ Various immunohistochemical markers that can help to the differential diagnosis of mesothelioma or adenocarcinoma have become available. Most of these markers, such as BerEP4, CD15, the thyroid transcription factor (TTF-1) and carcinoembryonic antigen (CEA) stain adenocarcinomas whereas calretinin and CK5/6 are positive in both benign

Correspondence: Professor M-C Copin, Service d'Anatomie et Cytologie Pathologiques, Hôpital Calmette, CHRU, Bd J. Leclercq, 59037 Lille Cedex, France.

E-mail: mc-copin@chru-lille.fr

Received 12 August 2003; revised 15 October 2003; accepted 16 October 2003; published online 5 December 2003 and malignant mesothelial cells. ${ }^{3-8}$ An appropriate panel of antibodies is useful to differentiate between mesothelioma and adenocarcinoma. Among markers of adenocarcinomas whatever their origin (CEA, BerEP4, CD15), BerEP4 is the most sensitive (80\%) but at the same time is the least specific. Moreover, the epitope recognized by this antibody is not yet characterized. ${ }^{4,8-11}$ Although it seems that LeuM1 (anti-CD15) may be specific, it is less sensitive than the other antibodies. ${ }^{12,13}$ Results on CEA sensitivity and specificity are very controversial in the literature due to the use of various monoclonal or polyclonal antibodies. In the largest series, CEA immunostaining is positive in about $90 \%$ of adenocarcinomas and weakly and focally positive in $10 \%$ of mesotheliomas. ${ }^{7,11,14}$ TTF-1 is selectively found in thyroid and lung cancers. It appears to be a sensitive $(70 \%)$ and highly specific marker for pulmonary adenocarcinomas correlated with morphologic resemblance to terminal respiratory unit cells..$^{8,15-17}$ 
Recently, E-cadherin has been tested in this issue. It is very often positive in adenocarcinomas but can be negative in poorly differentiated cases. Furthermore, $22 \%$ of mesotheliomas are stained with antiE-cadherin antibody.,16 MOC-31 immunostaining is also a useful marker of lung adenocarcinomas although positive immunostaining in a limited number of cells has been described in malignant mesotheliomas. ${ }^{18}$

The mesothelioma markers group includes CK5/6 and calretinin. The first one is positive in most of mesotheliomas and is frequently focally positive in endometrial $(50 \%)$, ovarian $(25 \%)$, breast ductal $(40 \%)$ and pancreatic (38\%) adenocarcinomas. Carcinomas with squamous differentiation and transitional cell carcinomas are diffusely positive. ${ }^{19}$ The second one, calretinin shows also reactivity in most of mesotheliomas (according to the used clone) with a typical cytoplasmic and nuclear staining. It is also positive, generally focally in $10 \%$ of adenocarcinomas of various origin. ${ }^{6,7,20}$ In spite of the use of several markers, the obtained profile is not always characteristic. For difficult cases, an adenocarcinomapositive marker which would be strongly specific and sensitive would be helpful to exclude mesothelioma.

Mucins constitute a heterogeneous group of highly $O$-glycosylated macromolecules synthesized by epithelial cells. They are characterized by a central core which is specific of each gene. It is made of tandemly repeated amino-acid regions wich are rich in proline, serine and threonine residues that serve as docking site for $O$-glycans. To date, eight human mucin genes: MUC1 to MUC4, MUC5AC, MUC5B, MUC6 and MUC7 have been well characterized from various epithelial tissues or mucosae, including airways. ${ }^{21-24}$ MUC4 has been initially isolated from a tracheobronchial mucosa
cDNA library by Porchet et $a 2^{25}$ and belongs to the membrane-bound mucin family with $\mathrm{MUC}^{26}$ and MUC3 ${ }^{27}$ Membrane-bound mucins are expressed in a wide range of mucous and nonmucous-secreting cells. They are involved in protection of epithelia but also in cellular adhesion, signal transduction and differentiation. ${ }^{28}$ MUC4 is expressed early in the primitive gut and is widely expressed in adult normal respiratory tissues. ${ }^{29-31}$ Moreover, MUC4 transcripts are frequently expressed in lung adenocarcinomas and epidermoid carcinomas. ${ }^{31-33}$ So, we postulated that mesothelial cells which are of mesodermic origin could not express MUC4.

The purpose of this study was to investigate the expression of apomucins especially MUC4 in malignant mesotheliomas and to determine the practical value of MUC4 immunostaining in distinguishing mesotheliomas from adenocarcinomas.

\section{Materials and methods}

\section{Patients and Tissues}

The cases used in this study were obtained from the files of the Department of Pathology at Calmette's hospital (CHR-U Lille) and are listed in Table 1.

The patient's characteristics were as follows: median age 57 years (range 35-76 years), 9:21 female/male ratio for adenocarcinomas and 66 years (range 50-77 years) and the same sex ratio for malignant mesotheliomas.

The group of malignant epithelial or mixed-type mesotheliomas of the pleura consisted of 39 formalin-fixed specimens (16 surgical resections and 23 biopsies) and two pleural effusions. The diagnostic criteria used for mesothelioma were clinical findings, typical histology on hematoxylin- and eosin-stained sections, negative immunoreactivity

Table 1 Results of MUC4 immunostaining on tissue samples and pleural effusions

\begin{tabular}{|c|c|c|c|c|c|c|}
\hline & \multirow[t]{2}{*}{ Total number of cases } & \multicolumn{5}{|c|}{ MUC4 immunoreactivity } \\
\hline & & Total of positive cases & +++ & ++ & + & - \\
\hline Malignant mesotheliomas & 41 & 0 & & & & \\
\hline Tissue samples & 39 & 0 & 0 & 0 & 0 & 39 \\
\hline Pleural effusions & 2 & 0 & 0 & 0 & 0 & 2 \\
\hline Normal and hyperplastic mesothelial cells & 32 & 0 & & & & \\
\hline Tissue samples & 12 & 0 & 0 & 0 & 0 & 12 \\
\hline Pleural effusions & 20 & 0 & 0 & 0 & 0 & 20 \\
\hline Lung adenocarcinomas & 45 & $40(88.9 \%)$ & & & & \\
\hline Tissue samples & 35 & $32(91.4 \%)$ & 12 & 11 & 9 & 3 \\
\hline Pleural effusions & 10 & $8(80 \%)$ & 7 & 1 & 0 & 2 \\
\hline Nonpulmonary adenocarcinomas & 21 & $12(57.1 \%)$ & & & & \\
\hline Tissue samples & 2 & & & & & \\
\hline Colon & 1 & 1 & 0 & 1 & 0 & 0 \\
\hline Endometrium & 1 & 0 & 0 & 0 & 0 & 1 \\
\hline Pleural effusions & 19 & $11(57.9 \%)$ & & & & \\
\hline Ovary & 2 & 2 & 2 & 0 & 0 & 0 \\
\hline Stomach & 2 & 2 & 2 & 0 & 0 & 0 \\
\hline Breast & 10 & 3 & 2 & 0 & 1 & 7 \\
\hline Unknown & 5 & 4 & 2 & 1 & 1 & 1 \\
\hline
\end{tabular}


for carcinoembryonic antigen (polyclonal, Dako, Glostrup, Denmark), Ber-EP4 (M0804, Dako, Glostrup, Denmark), CD15 (80H5, Immunotech, Marseille, France) and TTF-1 (8G7G3/1, Dako, Carpinteria, CA, USA) and positive staining for calretinin (Zymed, San Francisco, CA, USA) and cytokeratin 5/6 (D5/16B4, Chemicon, Temecula, CA, USA). Normal and hyperplastic mesothelial cells were studied in 20 paraffin-embedded cell blocks of pleural effusions and 12 formalin-fixed tissues. In the group of pleural effusions, the absence of carcinomatous cells was assessed both by cytologic examination and negative staining for BerEP4.

In all, 35 of the 45 specimens of lung adenocarcinomas were surgical resections and the remaining were cell blocks of pleural effusions. On surgical resections, all the adenocarcinomas studied expanded at least to the visceral pleura. The lung adenocarcinomas were diagnosed using World Health Organization criteria. ${ }^{34}$ A total of 20 were of the acinar type, five of papillary type and 10 of solid with mucin production type. The expression of cytokeratin 7 (OVTL12, Dako, Glostrup, Denmark) and TTF-1 was evaluated to support the pulmonary origin of the tumor.

The nonpulmonary adenocarcinomas $(n=21$, two surgical resections and 19 cells blocks of pleural effusions) consisted of 10 breast adenocarcinomas, two ovarian adenocarcinomas, one colon adenocarcinoma, two gastric adenocarcinomas, one endometrial carcinoma and five TTF-1 negative carcinomas of unknown origin, all metastatic to the pleura.

In the group of pleural effusions, whatever the origin, the presence of carcinomatous cells was assessed by cytologic examination and positive immunostaining for BerEP4.

For RNA analysis, samples were collected from cases undergoing surgery and pleural effusions. Tissues and cells were frozen in liquid nitrogen (for RT-PCR analysis) or immediatly fixed in fresh $10 \%$ neutral formaldehyde solution ( $\mathrm{pH} 7.4$ ) in phosphate buffer (for in situ hybridization).

\section{Immunohistochemistry}

Staining procedures were conducted using an automated immunostainer (ES, Ventana medical Systems, Strasbourg, France) on $3 \mu$ m-thick sections of paraffin-embedded tissue. Microwave pretreatment in citrate buffer ( $\mathrm{pH}$ 6.0) was performed for two $10 \mathrm{~min}$ cycles on tissue sections. The sections were incubated for $32 \mathrm{~min}$ with normal goat serum to block the nonspecific antibody binding sites. Sections were then incubated with the primary antiMUC4 polyclonal antibody, recognizing the tandem repeat sequences of this apomucin (purified rabbit polyclonal antibody, 1:50 dilution) ${ }^{35}$ for $32 \mathrm{~min}$. The immunohistochemistry method used a three-step undirect process based on the biotin-streptavidin complex. Slides were counterstained with hemato- xylin. Endogeneous peroxidase activity was suppressed by first incubating the specimen in $3 \%$ hydrogen peroxide. Positive and negative controls were added on each automated immunohistochemistry run. Negative controls consisted of (a) slides run without the primary antibody and (b) negative tissues for MUC4 by in situ hybridization (vessels, muscle and colon). Positive controls consisted of normal bronchus that has been shown to express MUC4 predominantly in their surface epithelium. ${ }^{32,33}$ The grading of the immunostaining was performed according to the percentage of reactive cells (negative $\pm=<1 \%$; weak $+=1-40 \%$; moderate $++=41-70 \%$; strong $+++=71-100 \%$ ).

\section{In situ Hybridization}

The samples were cut under sterile conditions ( $3 \mu \mathrm{m}$ thick sections) and put on silan-covered slides. Morphological control of the same blocks was obtained by stained sections with hematoxylineosin-saffron (HES) and astra blue.

Oligonucleotides corresponding to the tandem repeat sequences of MUC1, MUC2, MUC3, MUC4, MUC5AC, MUC5B, MUC6 and MUC7 genes were ${ }^{35}$ S-labeled as previously described. ${ }^{29,30}$

The samples were processed according to the previously described protocol. ${ }^{30}$ The sections were developed after 3 weeks and counterstained with methyl green pyronin (Sigma Chemical Co, St Louis, MO, USA).

Controls consisted of (a) competition studies with 50 -fold excess of unlabeled relevant and irrelevant oligonucleotides, (b) careful examination of non epithelial structures on the slides: vessels, muscle and connective tissue (negative control) and (c) a representative sample was chosen by morphological examination including both carcinoma and a normal bronchiole or bronchus used as an internal positive control.

The results were evaluated in a blinded manner by two pathologists experienced in pulmonary pathology. Scoring of reactions was performed semiquantitatively according to the intensity of labeling (absent $=-;+$, weak: visible at magnification $\times 200=+$; moderate: visible at magnification $\times 100=++$; strong: visible at magnification $\times 25=+++$ ).

\section{Reverse Transcriptase Polymerase Chain Reaction}

Total cellular RNA was isolated from thick cuts of 12 frozen tissue samples and from five pleural effusions using the Rneasy Midi ${ }^{\mathrm{TM}}$ kit (Qiagen) according to the manufacturer's instructions. Morphological control was done on $4-\mu \mathrm{m}$ sections of each specimen. Total RNA ( $1 \mu \mathrm{g})$ was reverse-transcribed using the advantage ${ }^{\mathrm{TM}}$ RT-for-PCR kit (Clontech) with the oligo dT primers. PCR analyses were performed using a Perkin-Elmer Thermal Cycler 2400 (Applied 
Biosystems) with sens primer NAU 511 (nt 29943014) and antisens primer NAU 533 (nt 3302-3322) (Gen Bank $^{\mathrm{TM}}$ accession number AJ010901) for the MUC4 gene expression analysis. ${ }^{23}$ A glyceraldehyde-3-phosphate deshydrogenase fragment was also amplified as control. PCR amplification reactions were conducted in $50 \mu \mathrm{l}$ reaction volumes containing $5 \mu \mathrm{l} 10 \times$ buffer, $5 \mu \mathrm{l} \mathrm{MgCl}_{2} 25 \mu \mathrm{M}, 5 \mu \mathrm{l}$ dNTPs $2.5 \mu \mathrm{M}, 10$ pmol of each primer, $2 \mathrm{U}$ of Ampli Taq Gold ${ }^{\mathrm{TM}}$ (Applied Biosystems) and 2-5 $\mu \mathrm{l}$ of cDNA. The cycle parameters were $94^{\circ} \mathrm{C}$ for $4 \mathrm{~min}$, followed by 30 cycles at $94^{\circ} \mathrm{C}$ for $30 \mathrm{~s}$, annealing at $60^{\circ} \mathrm{C}$ for $30 \mathrm{~s}$ and extension at $72{ }^{\circ} \mathrm{C}$ for $1 \mathrm{~min}$. The final elongation step was extended for an additional $15 \mathrm{~min}$ at $72^{\circ} \mathrm{C}$. PCR products were analyzed by $1.5 \%$ agarose gel electrophoresis in Tris/borate/ EDTA buffer and visualized with ethidium bromide.

\section{Results}

The results of immunostaining are summarized in Table 1

\section{Malignant Mesotheliomas and Normal Mesothelial Cells}

None of the malignant mesotheliomas, nor normal or hyperplastic mesothelial cells reacted with the antiMUC4 antibody (Figure 1).

MUC4 mRNAs were not detected both by in situ hybridization $(n=12)$ and RT-PCR analysis $(n=7$ : five tissue samples and two pleural fluids) in malignant mesotheliomas and by RT-PCR analysis in two noncancerous pleural fluids (Table 2).

The in situ hybridization study was completed for the other well characterized apomucin genes. MUC1, MUC2, MUC3, MUC5AC, MUC5B, MUC6 and $M U C 7$ transcripts were not found in the six samples of malignant mesotheliomas tested.

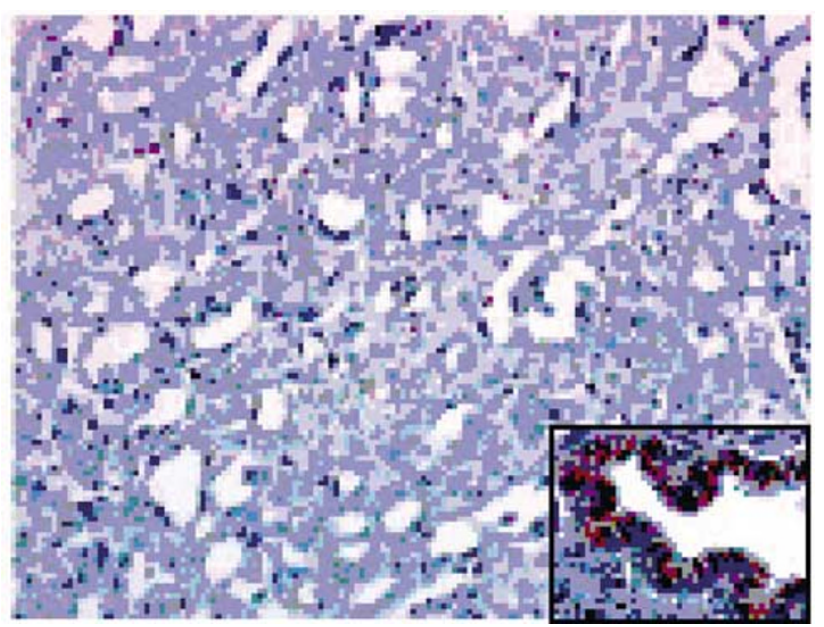

Figure 1 Malignant mesothelioma. Absence of MUC4 expression by immunohistochemistry $(\times 200)$. Inset: Normal MUC4 positive bronchiolar epithelium $(\times 200)$.

\section{Lung Adenocarcinomas}

\section{Surgical resections}

In all, 35 of $35(100 \%)$ of lung adenocarcinomas expressed cytokeratin 7. Of 35 lung adenocarcinomas 30 were TTF-1 positive. The five cases negative for TTF-1 immunostaining had a typical clinical presentation of lung carcinoma and were carcinomas of large bronchi. Reactivity with anti-MUC4 antibody was noted in 32 of 35 cases. MUC4 positivity was characterized by diffuse cytoplasmic staining (Figure 2) and less frequently membrane staining (Figure 3 ). In 12 of 20 cases with weak $(+)$ or moderate $(++)$ staining, carcinomatous cells immunoreactive for MUC4 were significantly more numerous beneath the pleura and in the pleural extension zone. In the deeper part of the tumor and at the front progression, the staining was more heterogeneous. In these cases, expression of cytokeratin 7 was homogeneous and diffuse, excluding a fixation artifact. In cases $+++(12 /$ 35), staining was intense and diffuse on the whole specimen (Figure 4). Only one of the five cases

Table 2 Results of MUC4 gene expression by RT-PCR

\begin{tabular}{lcc}
\hline & $\begin{array}{c}\text { Total } \\
\text { number of } \\
\text { cases tested }\end{array}$ & $\begin{array}{c}\text { Number of } \\
\text { positive } \\
\text { cases }\end{array}$ \\
\hline Malignant mesotheliomas & 7 & 0 \\
$\quad$ Tissue samples & 5 & 0 \\
$\quad$ Pleural effusions & 2 & 0 \\
Noncancerous pleural & 2 & 0 \\
effusions & 7 & 7 \\
Lung adenocarcinomas & 6 & 6 \\
$\quad$ Tissue samples & 1 & 1 \\
Pleural effusions & 1 & 1 (Colon) \\
Nonpulmonary & & 0 \\
adenocarcinomas & 1 & \\
$\quad$ Tissue samples & 0 & \\
Pleural effusions & &
\end{tabular}

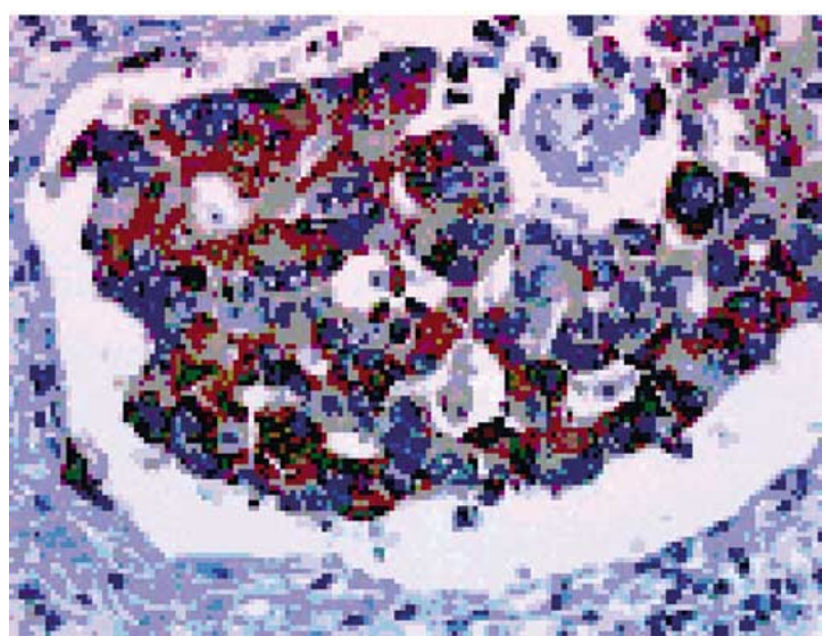

Figure 2 Lung adenocarcinoma. MUC4 immunostaining. Strong cytoplasmic MUC4 expression by carcinomatous cells $(\times 200)$. 


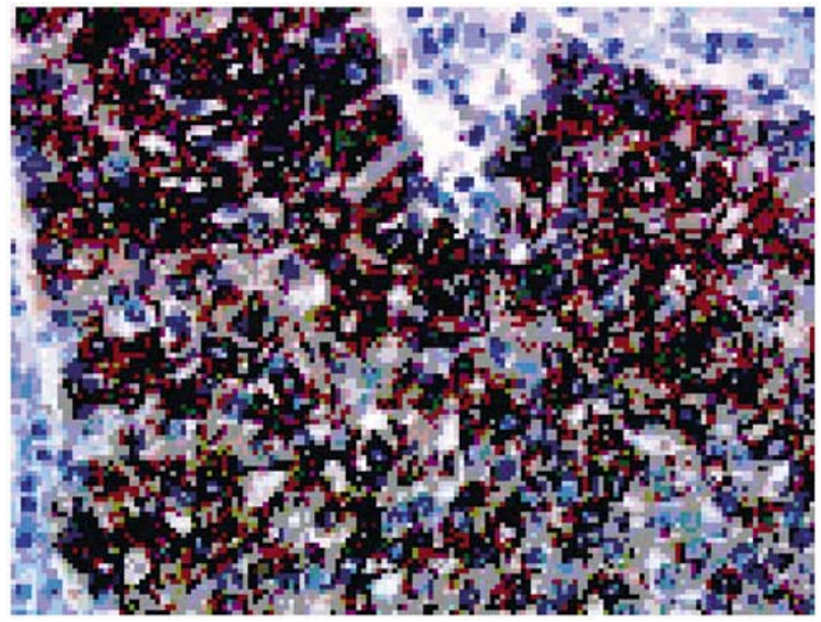

Figure 3 Lung adenocarcinoma. MUC4 immunostaining. Strong cytoplasmic and cell membrane MUC4 expression by carcinomatous cells $(\times 200)$.

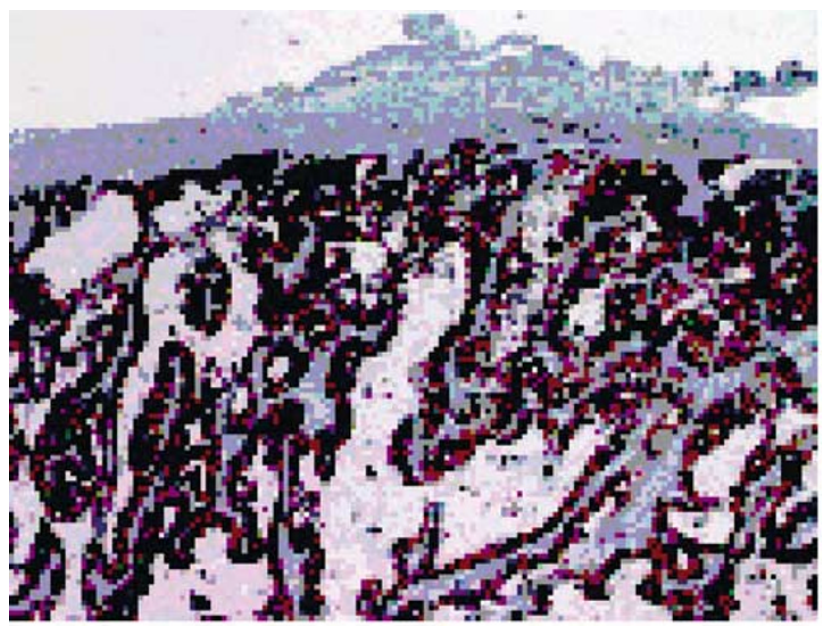

Figure 4 Lung adenocarcinoma invading the pleura. MUC4 immunostaining. Strong and diffuse MUC4 expression by carcinomatous cells $(\times 25)$.

Table 3 MUC4/TTF-1 immunoreactivity in lung adenocarcinomas (tissue samples)

\begin{tabular}{lcc}
\hline & $T T F-1+\mathrm{n}=30$ & $T T F-1-\mathrm{n}=5$ \\
\hline MUC4 $+n=32$ & 28 & 4 \\
MUC4 $-n=3$ & 2 & 1
\end{tabular}

negative for TTF-1 immunostaining was MUC4 negative (Table 3 ).

MUC4 mRNAs were detected by RT-PCR in the six cases tested, all positive for MUC4 protein expression by immunohistochemistry (Table 2). Frozen tissue was not available for the three MUC4-negative tissue samples by immunohistochemistry.

On the same blocks, MUC4 was expressed in normal type II pneumocytes $(n=7)$, in type II pneumocyte hyperplasia $(n=10)$ and in atypical pneumocyte hyperplasia $(n=7)$ adjacent to carcinoma by immunohistochemistry.

\section{Pleural effusions}

Eight of 10 cases contained numerous MUC4positive cells. The two cases negative for MUC4 immunostaining were TTF-1 positive. RT-PCR analysis was performed in only one case with frozen material available. This case, also positive for MUC4 at protein level, expressed MUC4 mRNA (Table 2).

\section{Nonpulmonary Adenocarcinomas}

Three of 10 cases of breast adenocarcinoma, two of two cases of ovarian carcinoma, two of two cases of gastric adenocarcinoma, one of one case of colon adenocarcinoma and four of five cases of unknown origin expressed MUC4 protein by immunohistochemistry. Among the negative cases, seven were metastasis from breast carcinomas, one from endometrial carcinoma and one from unknown origin. One case of colon adenocarcinoma expressing MUC4 by immunohistochemistry was tested by RT-PCR analysis, showing a positive but low signal with this technique (Table 2).

\section{Discussion}

Our previous results on MUC4 expression in lung carcinomas suggest that among mucins, MUC4 could be of diagnostic value to differentiate between adenocarcinoma and malignant mesothelioma as a specific marker of adenocarcinoma. ${ }^{32,33}$ First, we have postulated that mesothelial cells, that derivate from the mesoderm, do not express apomucins, especially MUC4, which is frequently expressed in many types of adenocarcinomas of various origin and in normal tissues of endodermic origin. ${ }^{29}$ In normal airways, MUC4 is expressed independently of mucus secretion by basal cells and ciliated cells as well as collecting ducts and goblet cells. ${ }^{29-31}$ Here, we have studied MUC4 expression by immunohistochemistry in malignant mesotheliomas and adenocarcinomas invading the pleura and the expression of MUC1-MUC4, MUC5AC, MUC5B, MUC6 and MUC7 genes by in situ hybridization in malignant mesotheliomas.

In our study, 32 of 35 (91.4\%) lung adenocarcinomas reacted with the anti-MUC4 antibody on formalin-fixed paraffin-embedded tissue. Although we have frequently observed both membrane and cytoplasmic immunostaining for MUC4 in carcinomas, some specimens have shown exclusive cytoplasmic staining as in normal bronchus. The fact that the tandem repeat on the MUC4 core might be masked by long and branched carbohydrate chains bound to the core protein at the cell surface could explain the failure to detect MUC4 membrane expression in normal cells and some carcinomas. Underglycosylation of mucins in cancers is well 
known and could explain the detection of membrane staining in the other cases of adenocarcinomas. ${ }^{36}$

MUC4 gene expression has been previously reported in 34 lung adenocarcinomas (17 of nonbronchioloalveolar and 17 of bronchioloalveolar type), by in situ hybridization ${ }^{33}$ whatever the histological subtype according to the WHO classification. ${ }^{34}$ MUC4 mRNA expression has also been described in lung carcinomas by Northern blot analysis and RT-PCR. ${ }^{37-39}$ In this study, we confirmed the frequent expression of both MUC4 protein and transcripts in lung adenocarcinomas.

According to literature and the results of our study, it seems that reactivity for MUC4 depends on the primary site of the tumor and has to be more extensively studied on paraffin-embedded tissue. MUC4 gene expression has been described in nonpulmonary adenocarcinomas of various origin including those of the pancreas, the biliary tract, the stomach, the colon, the endocervix and the ovary. ${ }^{40-45}$ In the current study, it seems that MUC4 has a lower sensitivity $(57.1 \%)$ in differentiating adenocarcinomas of nonpulmonary origin from mesotheliomas, especially for breast carcinomas, although the specimens tested were pleural effusions. We detected only three MUC4-positive cases of the 10 pleural metastatic effusions of breast carcinomas. Data about MUC4 expression in breast carcinomas are deduced from studies about deregulation of sialomucin complex (SMC), the rat homologue of the human mucin MUC4 isolated from the highly metastatic ascites 13762 mammary adenocarcinoma cells. ${ }^{46}$ There is only one study carried on the Muc4/SMC expression in mammary carcinomatous cells in pleural fluids. In all, 10 fluids out of the 10 tested were positive. ${ }^{47}$ Whether MUC4 expression in breast carcinomas is correlated to cancer agressiveness has never been studied.

Calretinin seems to be the most useful marker for the positive identification of malignant mesotheliomas with specificity over $90 \%$ for epithelioid mesotheliomas when compared with metastatic adenocarcinomas. ${ }^{6}$ Calretinin immunoreactivity has been reported focally in $10 \%$ of adenocarcinomas of various origin. More exactly, a nuclear staining has been detected in $6 \%$ of pulmonary adenocarcinomas ${ }^{3}$ and in a few cases of metastasis especially from breast, ${ }^{6,48}$ kidney, ${ }^{49,50}{ }^{\text {colon }}{ }^{20}$ and pancreas $^{6}$ carcinomas. Although most studies have indicated that BerEP4 immunostaining is helpful in separating pleural mesotheliomas from lung adenocarcinomas, mesotheliomas frequently show reactivity in a limited number of cells. For example, Ordonez ${ }^{8}$ obtained membrane staining with BerEP4 antibody in 18 of 70 (26\%) epithelial pleural mesotheliomas. We have shown that the specificity of MUC4 immunostaining was very high $(100 \%)$ in distinguishing malignant mesothelioma from adenocarcinoma. Indeed, we did not encounter any immunoreactive neoplastic cells in the 41 malignant mesotheliomas included in the current investigation. Moreover, we did not detect MUC4 mRNA in mesotheliomas by two different techniques, that is, in situ hybridization and RT-PCR. MUC4 reactivity, even in a limited number of cells could exclude the diagnosis of malignant mesothelioma especially in difficult cases when calretinin expression is low or BerEP4 staining focally positive. Moreover, according to our results, a phenotype MUC4 + calretinin + could exclude the diagnosis of malignant mesothelioma. Therefore, MUC4 antibody may be a useful adjunct in the immunohistochemical diagnosis of mesothelioma. In the current study, we have also shown that malignant mesotheliomas did not express the other well-characterized MUC1, MUC2, MUC3, MUC5AC, MUC5B, MUC6 and MUC7 genes by in situ hybridization analysis.

In addition, we showed that normal and hyperplastic mesothelial cells did not express MUC4. Although our study focused on the practical use of MUC4 in differentiating mesothelioma from adenocarcinoma, we believe that this marker could also be of some help in the detection of carcinomatous cells in pleural effusions. MUC4 is also expressed by squamous cell carcinoma of various origin including lung. ${ }^{32}$ BerEP4 has a very high sensitivity in this setting $(80 \%)$, but normal or hyperplastic mesothelial cells can be stained. ${ }^{9,10}$ MUC4 expression has been detected in eight of $10(80 \%)$ cases of lung adenocarcinomas and eight of nine $(89 \%)$ cases of nonpulmonary carcinomas excluding breast origin. Although MUC4 seems to be less sensitive than BerEP4 but more specific, more extensive studies are necessary in this issue.

We observed MUC4 expression in both normal or hyperplastic pneumocytes, with or without atypia, adjacent to carcinoma, by immunohistochemistry whereas we did not detect MUC4 gene expression in normal type II pneumocytes by in situ hybridization. ${ }^{32}$ We have previously shown that MUC4 is the first mucin gene to be expressed, as early as 6.5 week after gestation, by the primitive epithelial cells which have the potential to differentiate in all the epithelial cell types of the conducting airways and alveolar epithelium. ${ }^{30}$ TTF-1 is now recognized as a lineage marker of terminal respiratory unit. ${ }^{17}$ Its expression is also initiated at a very early stage of lung morphogenesis but shifted to the peripheral airway epithelium once peripheral airway tubes are developed. In normal adult tissue, TTF-1 expression is restricted to pneumocytes and epithelium of bronchioles. Whereas TTF-1 has a crucial role in the development of the terminal respiratory unit, MUC4 has probably a great importance both in the early stages of lung development and in the whole process of cell differentiation.

Several arguments suggest that MUC4 plays a role in tumour-cell invasion and metastasis. MUC4 is a transmembrane molecule with a large extracellular domain protruding high above the cell surface thought to reduce cell-cell and extracellular 
matrix-cell adhesion in cancer cells ${ }^{46}$ and to block immune cell killing of mucin-expressing tumor cells. ${ }^{47}$ Moreover, MUC4 has two EGF-like domains, one of which can act as an intramembrane ligand/ modulator for the tyrosine kinase ErbB2 and could be involved in cellular signaling. ${ }^{51}$ However, direct evidence of the role of MUC4 in tumor progression is lacking. In our study, although some lung adenocarcinomas were immunostained strongly and in a large proportion of carcinomatous cells, we noticed that the MUC4 expression was frequently heterogeneous within the same tumor. In these cases, we observed that MUC4 expression was more frequent in carcinomatous cells invading the pleura. The higher expression of MUC4 in the pleural infiltration zone suggests that MUC4 may play a role in tumor progression in lung adenocarcinomas, pleural involvement being recognized as a significant predictor of local or regional tumor spread. ${ }^{52}$

In summary, MUC4 is very frequently expressed in lung adenocarcinomas and preferentially by the carcinomatous cells involved in pleural spread. Moreover, MUC4 is undetectable in benign and tumoral mesothelial cells. Our study using several complementary techniques allows to validate the use of anti-MUC4 antibody by immunohistochemistry in the differential diagnosis between malignant mesothelioma and lung adenocarcinoma. The usefulness of MUC4 expression in the detection of carcinomatous cells in pleural effusions has to be more extensively studied.

\section{Acknowledgements}

We acknowledge Ms E Deschodt, Ms MC Dieu, Ms A Bernigaud, Ms V Dumetz, Ms V Vervaecke and Mr M Samain for excellent technical assistance.

\section{References}

1 Brockstedt U, Gulyas M, Dobra K, et al. An optimized battery of eight antibodies that can distinguish most cases of epithelial mesothelioma from adenocarcinoma. Am J Clin Pathol 2000;114:203-209.

2 Galateau-Salle F. Recent data in the diagnosis of pleural mesothelioma, a lesional spectrum which never ceases to amaze us. Ann Pathol 2000;20: S45-S50.

3 Abutaily AS, Addis BJ, Roche WR. Immunohistochemistry in the distinction between malignant mesothelioma and pulmonary adenocarcinoma: a critical evaluation of new antibodies. J Clin Pathol 2002;55:662-668.

4 Carella R, Deleonardi G, D’Errico A, et al. Immunohistochemical panels for differentiating epithelial malignant mesothelioma from lung adenocarcinoma: a study with logistic regression analysis. Am J Surg Pathol 2001;25:43-50.
5 Comin CE, Novelli L, Boddi V, et al. Calretinin, thrombomodulin, CEA, and CD15: a useful combination of immunohistochemical markers for differentiating pleural epithelial mesothelioma from peripheral pulmonary adenocarcinoma. Hum Pathol 2001;32: 529-536.

6 Doglioni C, Tos AP, Laurino L, et al. Calretinin: a novel immunocytochemical marker for mesothelioma. Am J Surg Pathol 1996;20:1037-1046.

7 Ordonez NG. Role of immunohistochemistry in differentiating epithelial mesothelioma from adenocarcinoma. Review and update. Am J Clin Pathol 1999;112: 75-89.

8 Ordonez NG. Value of the Ber-EP4 antibody in differentiating epithelial pleural mesothelioma from adenocarcinoma. The M.D. Anderson experience and a critical review of the literature. Am J Clin Pathol 1998;109:85-89.

9 Diaz-Arias AA, Loy TS, Bickel JT, et al. Utility of BEREP4 in the diagnosis of adenocarcinoma in effusions: an immunocytochemical study of 232 cases. Diagn Cytopathol 1993;9:516-521.

10 Nagel H, Hemmerlein B, Ruschenburg I, et al. The value of anti-calretinin antibody in the differential diagnosis of normal and reactive mesothelia versus metastatic tumors in effusion cytology. Pathol Res Pract 1998;194:759-764.

11 Riera JR, Astengo-Osuna C, Longmate JA, et al. The immunohistochemical diagnostic panel for epithelial mesothelioma: a reevaluation after heatinduced epitope retrieval. Am J Surg Pathol 1997;21: 1409-1419.

12 Bateman AC, Al-Talib RK, Newman T, et al. Immunohistochemical phenotype of malignant mesothelioma: predictive value of CA125 and HBME-1 expression. Histopathology 1997;30:49-56.

13 Ordonez NG. The immunohistochemical diagnosis of mesothelioma. Differentiation of mesothelioma and lung adenocarcinoma. Am J Surg Pathol 1989;13: 276-291.

14 Dejmek A, Hjerpe A. Carcinoembryonic antigen-like reactivity in malignant mesothelioma. A comparison between different commercially available antibodies. Cancer 1994;73:464-469.

15 Hecht JL, Pinkus JL, Weinstein LJ, et al. The value of thyroid transcription factor-1 in cytologic preparations as a marker for metastatic adenocarcinoma of lung origin. Am J Clin Pathol 2001;116:483-488.

16 Ordonez NG. Value of thyroid transcription factor-1, Ecadherin, BG8, WT1, and CD44S immunostaining in distinguishing epithelial pleural mesothelioma from pulmonary and nonpulmonary adenocarcinoma. Am J Surg Pathol 2000;24:598-606.

17 Yatabe Y, Mitsudomi T, Takahashi T. TTF-1 expression in pulmonary adenocarcinomas. Am J Surg Pathol 2002;26:767-773.

18 Ordonez NG. The immunohistochemical diagnosis of mesothelioma: a comparative study of epithelioid mesothelioma and lung adenocarcinoma. Am J Surg Pathol 2003;27:1031-1051.

19 Chu PG, Weiss LM. Expression of cytokeratin 5/6 in epithelial neoplasms: an immunohistochemical study of 509 cases. Mod Pathol 2002;15:6-10.

20 Gotzos V, Wintergerst ES, Musy JP, et al. Selective distribution of calretinin in adenocarcinomas of the human colon and adjacent tissues. Am J Surg Pathol 1999;23:701-711. 
21 Biesbrock AR, Bobek LA, Levine MJ. MUC7 gene expression and genetic polymorphism. Glycoconj J 1997;14:415-422.

22 Moniaux N, Escande F, Porchet N, et al. Structural organization and classification of the human mucin genes. Front Biosci 2001;6:D1192-D1206.

23 Moniaux N, Nollet S, Porchet N, et al. Complete sequence of the human mucin MUC4: a putative cell membrane-associated mucin. Biochem J 1999;338: 325-333.

24 Van Klinken BJ, Dekker J, Buller HA, et al. Mucin gene structure and expression: protection vs adhesion. Am J Physiol 1995;269:G613-G627.

25 Porchet N, Nguyen VC, Dufosse J, et al. Molecular cloning and chromosomal localization of a novel human tracheo-bronchial mucin cDNA containing tandemly repeated sequences of 48 base pairs. Biochem Biophys Res Commun 1991;175:414-422.

26 Gendler SJ, Spicer AP, Lalani EN, et al. Structure and biology of a carcinoma-associated mucin, MUC1. Am Rev Respir Dis 1991;144:S42-S47.

27 Williams SJ, Munster DJ, Quin RJ, et al. The MUC3 gene encodes a transmembrane mucin and is alternatively spliced. Biochem Biophys Res Commun 1999;261:83-89.

28 Porchet N, Buisine MP, Desseyn JL, et al. MUC genes: a superfamily of genes? Towards a functional classification of human apomucins. J Soc Biol 1999;193:85-99.

29 Audie JP, Janin A, Porchet N, et al. Expression of human mucin genes in respiratory, digestive, and reproductive tracts ascertained by in situ hybridisation. J Histochem Cytochem 1993;41:1479-1485.

30 Buisine MP, Devisme L, Copin MC, et al. Developmental mucin gene expression in the human respiratory tract. Am J Respir Cell Mol Biol 1999;20:209-218.

31 Copin MC, Devisme L, Buisine MP, et al. From normal respiratory mucosa to epidermoid carcinoma: expression of human mucin genes. Int J Cancer 2000;86: 162-168.

32 Copin MC, Buisine MP, Devisme L, et al. Normal respiratory mucosa, precursor lesions and lung carcinomas: differential expression of human mucin genes. Front Biosci 2001;6:D1264-D1275.

33 Copin MC, Buisine MP, Leteurtre E, et al. Mucinous bronchioloalveolar carcinomas display a specific pattern of mucin gene expression among primary lung adenocarcinomas. Hum Pathol 2001;32:274-281.

34 Travis WD, Colby TV, Corrin B, et al. Histological typing of lung and pleural tumors. International Histological Classification of Tumors. 3d ed. WHO: Geneva, 1999.

35 Lopez-Ferrer A, de Bolos C, Barranco C, et al . Role of fucosyltransferases in the association between apomucin and Lewis antigen expression in normal and malignant gastric epithelium. Gut 2000;47:349-356.

36 Wittel UA, Goel A, Varsney GC, et al. Mucin antibodies-new tools in diagnosis and therapy of cancer. Front Biosci 2001;6:D1296-D1310.

37 Lopez-Ferrer A, Curull V, Barranco C, et al. Mucins as differentiation markers in bronchial epithelium. Squamous cell carcinoma and adenocarcinoma display similar expression patterns. Am J Respir Cell Mol Biol 2001;24:22-29.

38 Nguyen PL, Niehans GA, Cherwitz DL, et al. Membrane-bound (MUC1) and secretory (MUC2, MUC3, and MUC4) mucin gene expression in human lung cancer. Tumour Biol 1996;17:176-192.

39 Seregni E, Botti C, Lombardo C, et al. Pattern of mucin gene expression in normal and neoplastic lung tissues. Anticancer Res 1996;16:2209-2213.

40 Balague $\mathrm{C}$, Audié JP, Porchet $\mathrm{N}$, et al. In situ hybridization shows distinct patterns of mucin gene expression in normal, benign, and malignant pancreas tissues. Gastroenterology 1995;109:953-964.

41 Biemer-Huttmann AE, Walsh MD, Mc Guckin MA, et al. Mucin core protein expression in colorectal cancers with high levels of microsatellite instability indicates a novel pathway of morphogenesis. Clin Cancer Res 2000;6:1909-1916.

42 Buisine MP, Devisme L, Maunoury V, et al. Developmental mucin gene expression in the gastroduodenal tract and accessory digestive glands. I. Stomach. A relationship to gastric carcinoma. J Histochem Cytochem 2000;48:1657-1666.

43 Giuntoli RL, Rodriguez GC, Whitaker RS, et al. Mucin gene expression in ovarian cancers. Cancer Res 1998;58:5546-5550.

44 Lee KT, Liu TS. Altered mucin gene expression in stone-containing intrahepatic bile ducts and cholangiocarcinomas. Dig Dis Sci 2001;46:2166-2172.

45 Lopez-Ferrer A, Alameda F, Barranco C, et al. MUC4 expression is increased in dysplastic cervical disorders. Hum Pathol 2001;32:1197-1202.

46 Komatsu M, Tatum L, Altman NH, et al. Potentiation of metastasis by cell surface sialomucin complex (rat MUC4), a multifunctional anti-adhesive glycoprotein. Int J Cancer 2000;87:480-486.

47 Komatsu M, Yee L, Carraway KL. Overexpression of sialomucin complex, a rat homologue of MUC4, inhibits tumor killing by lymphokine-activated killer cells. Cancer Res 1999;59:2229-2236.

48 Kayser K, Bohm G, Blum S, et al. Glyco- and immunohistochemical refinement of the differential diagnosis between mesothelioma and metastatic carcinoma and survival analysis of patients. J Pathol 2001;193:175-180.

49 Martignoni G, Pea M, Chilosi M, et al. Parvalbumin is constantly expressed in chromophobe renal carcinoma. Mod Pathol 2001;14:760-767.

50 Osborn M, Pelling N, Walker MM, et al. The value of 'mesothelium-associated' antibodies in distinguishing between metastatic renal cell carcinomas and mesotheliomas. Histopathology 2002;41: 301-307.

51 Carraway KL, Rossi EA, Komatsu M, et al An intramembrane modulator of the ErbB2 receptor tyrosine kinase that potentiates neuregulin signaling. J Biol Chem 1999;274:5263-5266.

52 Suzuki K, Nagai K, Yoshida J, et al. Predictors of lymph node and intrapulmonary metastasis in clinical stage IA non-small cell lung carcinoma. Ann Thorac Surg 2001;72:352-356. 